\title{
Analysis of Factors Affecting Solidification Strength of Sludge in a Landfill Area of Shenzhen
}

\author{
Jihui Ding ${ }^{1,2}$, Tianyv Zhang1, Jie Huang'2, Wei Chen ${ }^{3}$ \\ ${ }^{1}$ College of Civil Engineering, Hebei University, Baoding, China \\ ${ }^{2}$ Beijing Aidi Geotechnical Investigation \& Foundation Engineering Company, Beijing, China \\ ${ }^{3}$ CCCC Road \& Bridge Special Engineering Co. Ltd., Wuhan, China \\ Email: aelmegharbel@eng.psu.edu.eg
}

How to cite this paper: Ding, J.H., Zhang, T.Y., Huang, J. and Chen, W. (2018) Analysis of Factors Affecting Solidification Strength of Sludge in a Landfill Area of Shenzhen. World Journal of Engineering and Technology, 6, 794-805.

https://doi.org/10.4236/wjet.2018.64052

Received: September 11, 2018

Accepted: October 10, 2018

Published: November 6, 2018

Copyright $\odot 2018$ by authors and Scientific Research Publishing Inc. This work is licensed under the Creative Commons Attribution International License (CC BY 4.0).

http://creativecommons.org/licenses/by/4.0/

\begin{abstract}
Parallel and orthogonal tests are used to explore the influence law of the dosage and age of curing agent on the strength of solidified sludge. The test results show that: 1) The strength of solidified sludge is mainly related to the cement content and dry soil content, and presents a good linear relationship. The influence of gypsum content is not significant. As the age increases, the strength is greatly affected by the cement content. 2) At different ages, the unconfined compression strength of solidified sludge presents a linear relationship, and the change law of later strength can be predicted by early strength. 3) Degree of influence of curing agent dosage: cement dosage > gypsum dosage $>$ dry soil dosage. The optimal mixture ratio is $8 \%$ of cement content, $30 \%$ of gypsum content (proportion of cement content), and 4 times of dry soil content (multiple of cement content).
\end{abstract}

\section{Keywords \\ Curing Agent, Unconfined Compression Strength, Parallel Test, Orthogonal Experiment}

\section{Open Access}

\section{Introduction}

Domestic treatment of sludge is mostly landfill methods. As a sludge product after sewage treatment, sludge has the characteristics of easy rancidity, high moisture content, low permeability coefficient and low strength. Therefore, nowadays, with insufficient urban development space, the sludge strength of sludge landfill site is difficult to meet the requirements of individual landfill or bear the 
upper load as foundation. The solidification treatment of sludge by some on-site solidification methods can make it meet the requirements of foundation filling and has important significance for eco-city construction [1]. In-situ curing achieves the solidification effect of the sludge by adding a solidified material to the soft soil to cement the soil particles and dissipate the water. Domestic research on in-situ curing has focused on the choice and ratio of curing agents. Zhang Chunlei [2] solidified the dredged mud by adding a curing agent, which verified that the in-situ solidification method can improve the strength, deformation and permeability of the dredged mud. Lin Anzhen [3] studied the effect of in-situ solidification and found that the solidified dredged mud can be used as a filling material in practical engineering and its feasibility is analyzed. Foreign scholar Sezer [4] et al. used lime and fly ash as curing agents to obtain the variation of sludge strength with the amount of curing agent through laboratory tests. Filz G M [5] et al. studied the strength of solidified sludge by incorporating different amounts of curing agent to obtain the best ratio of cement and fly ash solidified sludge. Lin [6] and Ouhadi [7] used slaked lime and lime-fly ash as sludge solidifying agents respectively to determine the appropriate mix ratio and verify its feasibility. By studying the effect of organic matter on the in-situ solidification method, Helene Tremblay [8] found that the strength of the solidified sludge decreased with the increase of the organic matter content in the curing agent. In the research of in-situ solidification method by domestic and foreign scholars, cement, fly ash, lime, slag and other solidified materials are often used as curing agents. In this paper, the dry soil rarely used in the study is used as in-situ solidified material, and combined with cement and gypsum; the effect of research on sludge strength is in a sludge landfill in Shenzhen.

\section{Test Materials and Methods}

\subsection{Test Materials}

The test uses the original sludge, which was taken from a sludge landfill in Shenzhen (as shown in Figure 1). After the sludge and curing agent of the sewage treatment plant were directly mixed and treated, the landfill was centralized. After that, it covers about $0.5 \mathrm{~m}$ of loess. After excavation on site, the odor emission was more obvious (mainly ammonia, hydrogen sulfide, methane and other gases generated by organic matter spoilage). The sludge was black peat-like, and the average natural moisture content of the average sludge was $105.4 \%$, the average specific gravity was 2.59 , the average natural density was $1.61 \mathrm{~g} / \mathrm{cm}^{3}$, and the average permeability coefficient was $2.65 \times 10^{-7} \mathrm{~cm} / \mathrm{s}$. The average content of particles of $\leq 0.075 \mathrm{~mm}$ in the sludge of the sludge landfill is about $40 \%$.

The sludge landfill soil belongs to peat silt, and the micro-structure image of sludge soil is shown in Figure 2. It can be seen from the figure that the soil is mostly in the form of massive structure, and the surface of the soil particles is attached with fluffy materials. Only a small amount of soil is in the form of a 


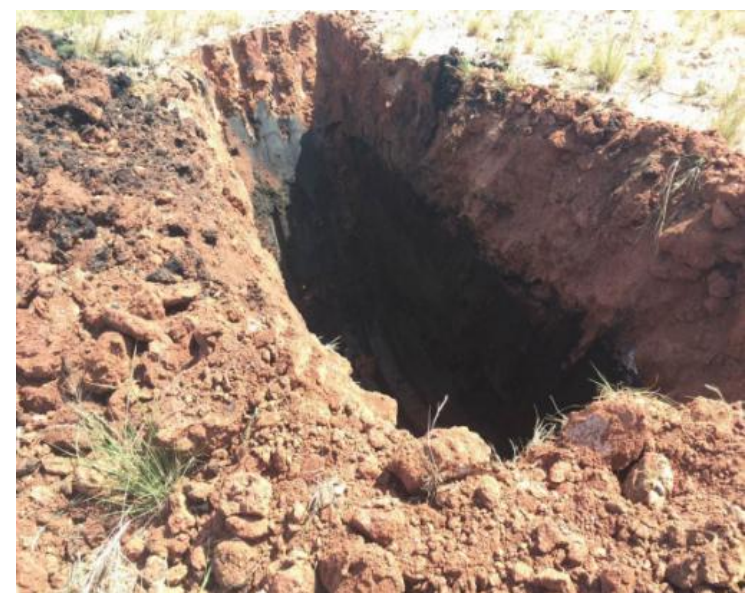

Figure 1. Sludge landfill upper layer covering soil $0.5 \mathrm{~m}$.

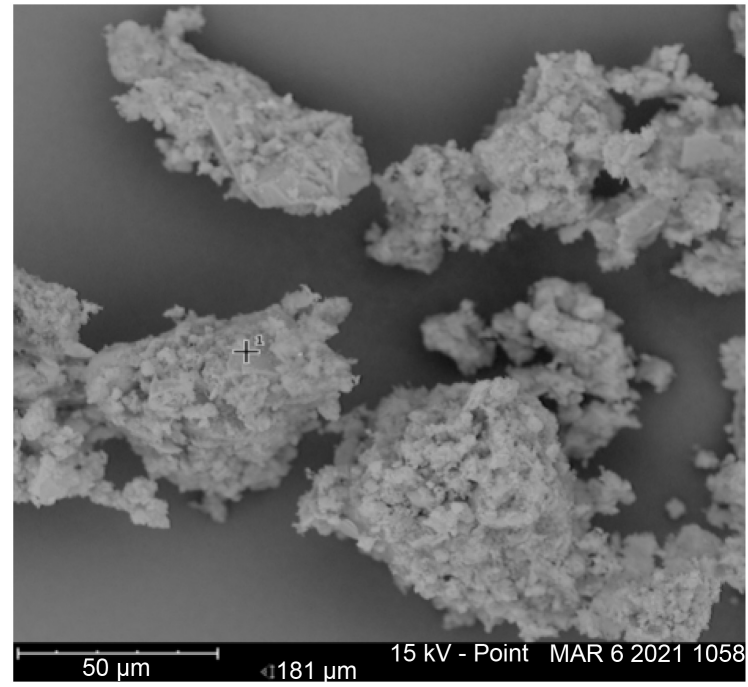

Figure 2. Undisturbed sludge microstructure image.

sheet, which is related to the addition of a large amount of flocculant to the sludge during the sewage treatment. Therefore, it has the characteristics of strong flocculation and high combined water content, which leads to the conventional curing method such as vacuum pre-pressing method and stacking pre-pressing method being too low in efficiency to achieve the curing effect. In this paper, cement is the main curing agent, and gypsum and dry soil are used as curing agent.

\subsection{Test Methods}

In this test, the YYW-1 manual lime soil unconfined pressure gauge (as shown in Figure 3) was used to measure the unconfined compressive strength. According to the steps in the specification, a cylindrical specimen with a diameter of $39.1 \mathrm{~mm}$ and a height of $80 \mathrm{~mm}$ was placed on the instrument. Then, by rocking the rocker, the platform below the sample is raised while applying vertical pressure to the soil sample until the sample is destroyed. The axial pressure 


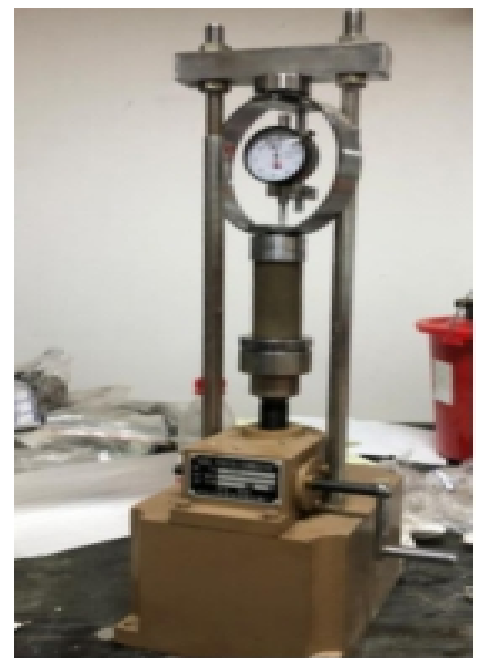

Figure 3. YYW-1 manual lime soil unconfined pressure gauge.

at which the sample is broken is called the unconfined compressive strength and is expressed by $\mathrm{q}_{\mathrm{u}}$.

According to the experience of the previous attempts in this study and the in-situ curing test [5], the gypsum content was selected as $0 \%, 20 \%, 30 \%, 40 \%$ of the cement content based on $8 \%$ of the cement content. $50 \%$. The dry soil was selected as 1 times, 2 times, 3 times and 4 times of the cement content. To investigate the curing effect, parallel tests and orthogonal tests were set up.

Parallel test, by controlling the amount of two additives unchanged, changing the amount of another additive, to achieve the principle of controlling a single variable, such as Table 1.

Orthogonal test, uses orthogonal tables to find better influence conditions from a small number of trials to achieve the best experimental results [9]. The test measures the degree of influence of the corresponding factors on the test results by the magnitude of the $\mathrm{R}$ value, and the greater the $\mathrm{R}$ value, the greater the influence. The test was designed according to the three factors and three levels, see Table 2, and from Table 2, the L9 $\left(3^{3}\right)$ orthogonal table was used to obtain the test plan, see Table 3.

\section{Test Results Analysis}

\subsection{Influence of Cement Content on Solidified Sludge Strength}

Table 4 shows the unconfined compression strength values of solidified soils with different formulations at different ages. Figure 4 shows the relationship between the unconfined compression strength of solidified soil and the amount of cement added. In the three stages of different ages, the unconfined compression strength of the solidified sludge is increasing during the process of increasing the cement content from $4 \%$ to $10 \%$, and the growth rate is above $60 \%$, up to $173.18 \%$. When the cement content increased from $8 \%$ to $10 \%$, the growth rate of each of the three curves was above $110 \%$. It can be seen that the strength of 
Table 1. Parallel test mix ratio (gypsum and dry soil are relative cement content).

\begin{tabular}{cccc}
\hline Group & Cement content & Gypsum content & Dry soil content \\
\hline 1.1 & $4 \%$ & $0 \%$ & 0 \\
1.2 & $6 \%$ & $0 \%$ & 0 \\
1.3 & $8 \%$ & $0 \%$ & 0 \\
1.4 & $10 \%$ & $0 \%$ & 0 \\
2.1 .1 & $8 \%$ & $20 \%$ & 0 \\
2.1 .2 & $8 \%$ & $30 \%$ & 0 \\
2.1 .3 & $8 \%$ & $40 \%$ & 0 \\
2.1 .4 & $8 \%$ & $50 \%$ & 0 \\
2.2 .1 & $8 \%$ & $0 \%$ & 1 Multiple \\
2.2 .2 & $8 \%$ & $0 \%$ & 2 Multiple \\
2.2 .3 & $8 \%$ & $0 \%$ & 3 Multiple \\
2.2 .4 & $8 \%$ & $0 \%$ & 4 Multiple \\
\hline
\end{tabular}

Table 2. Orthogonal test factor level table (gypsum and dry soil are relative cement content).

\begin{tabular}{cccc}
\hline Level & Cement & Plaster & Dry soil \\
\hline 1 & $4 \%$ & $10 \%$ & 2 Multiple \\
2 & $6 \%$ & $20 \%$ & 3 Multiple \\
3 & $8 \%$ & $30 \%$ & 4 Multiple \\
\hline
\end{tabular}

Table 3. Orthogonal test scheme (gypsum and dry soil are relative cement content).

\begin{tabular}{ccccc}
\hline Group & Cement content & Gypsum content & Dry soil content & Test results \\
\hline 3.1 & $4 \%$ & $10 \%$ & 2 Multiple & $\mathrm{X} 1$ \\
3.2 & $4 \%$ & $20 \%$ & 3 Multiple & $\mathrm{X} 2$ \\
3.3 & $4 \%$ & $30 \%$ & 4 Multiple & $\mathrm{X} 3$ \\
3.4 & $6 \%$ & $20 \%$ & 2 Multiple & $\mathrm{X} 4$ \\
3.5 & $6 \%$ & $30 \%$ & 3 Multiple & $\mathrm{X} 5$ \\
3.6 & $6 \%$ & $10 \%$ & 4 Multiple & $\mathrm{X} 6$ \\
3.7 & $8 \%$ & $30 \%$ & 2 Multiple & $\mathrm{X} 7$ \\
3.8 & $8 \%$ & $10 \%$ & 3 Multiple & $\mathrm{X} 8$ \\
3.9 & $8 \%$ & $20 \%$ & 4 Multiple & $\mathrm{X} 9$ \\
\hline
\end{tabular}

the sludge increased linearly with the increase of cement content.

\subsection{Effect of Gypsum Content on Solidified Sludge Strength}

Figure 5 shows the relationship between the strength of solidified sludge and the amount of gypsum, of which the cement addition is $8 \%$. The strength of solidified sludge increases first and then decreases with the increase of gypsum content, and when the gypsum content accounts for $30 \%$ of the cement content, the solidified sludge strength peaks, and the strength is about $30 \%$ higher than that 
Table 4. Summary of unconfined compression strength of each group in parallel test.

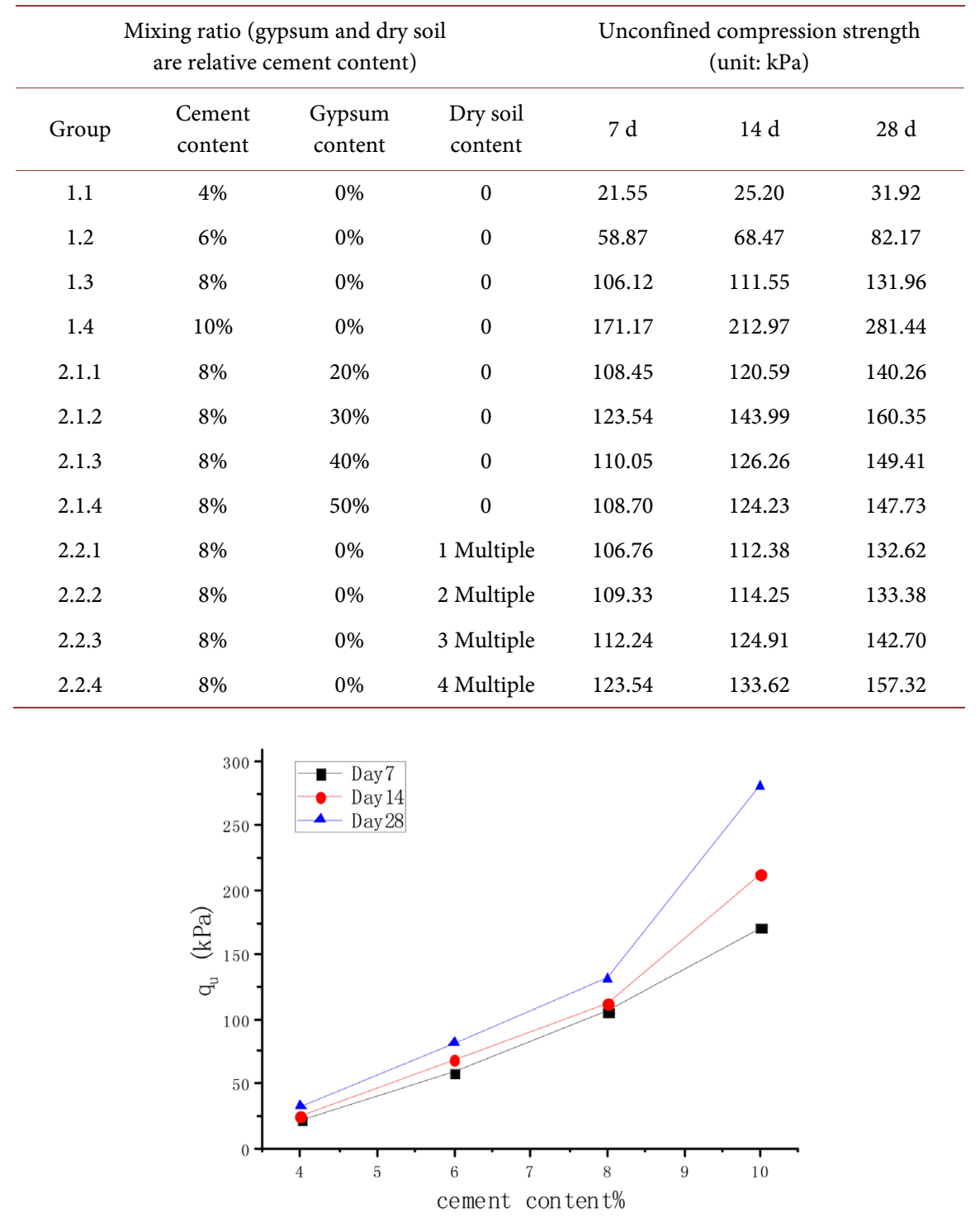

Figure 4. Relationship between $\mathrm{q}_{\mathrm{u}}$ and cement content.

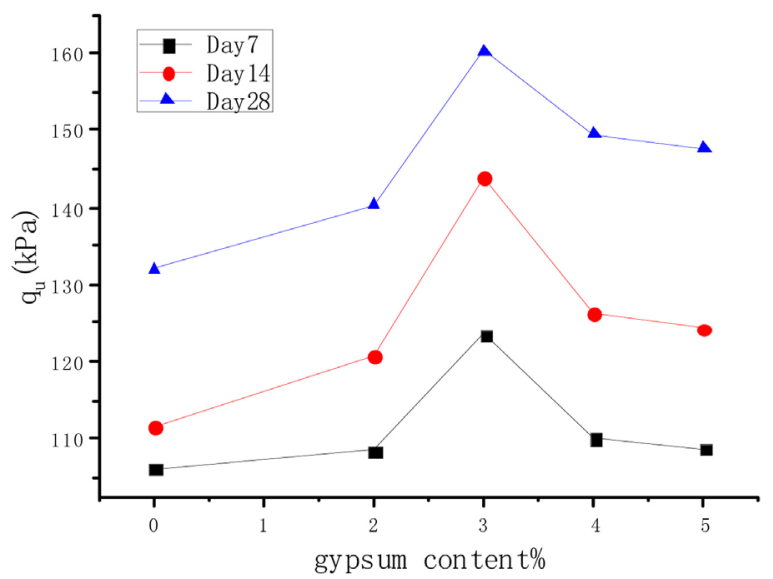

Figure 5. Relationship between $\mathrm{q}_{\mathrm{u}}$ and gypsum content. 
without adding gypsum.

\subsection{Influence of Gypsum Content on Solidified Sludge Strength}

Figure 6 shows the relationship between the solidified sludge strength and the dry soil content. When the age was $7 \mathrm{~d}$, the strength of the solidified sludge increased by $0.06 \%, 2.41 \%, 2.66 \%, 10.07 \%$ compared with the non-incorporated dry soil. The dry soil content was positively correlated with the solidified sludge strength. Under the dry soil content of 4 times the cement dosage, the unconfined compression strength at $7 \mathrm{~d}, 14 \mathrm{~d}$ and $28 \mathrm{~d}$ was increased by $16.42 \%$, $19.79 \%, 19.22 \%$ compared with that when not mixed with dry soil.

Figure 7 and Figure 8 are the fitting curves of the cement and dry soil content and the unconfined compression strength, which all conform to the fitting function $y=\mathrm{A} x+\mathrm{B}$ type, and when the cement acts alone, the coefficient $\mathrm{A}$ increases as the age increases. The fitting curve is shown in Table 5.

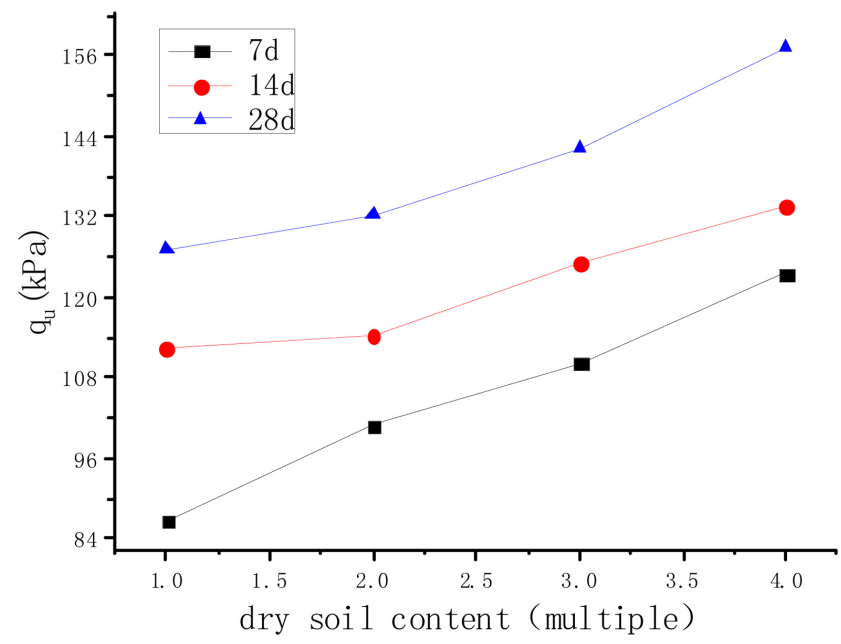

Figure 6. Relationship between $\mathrm{q}_{\mathrm{u}}$ and dry soil content.

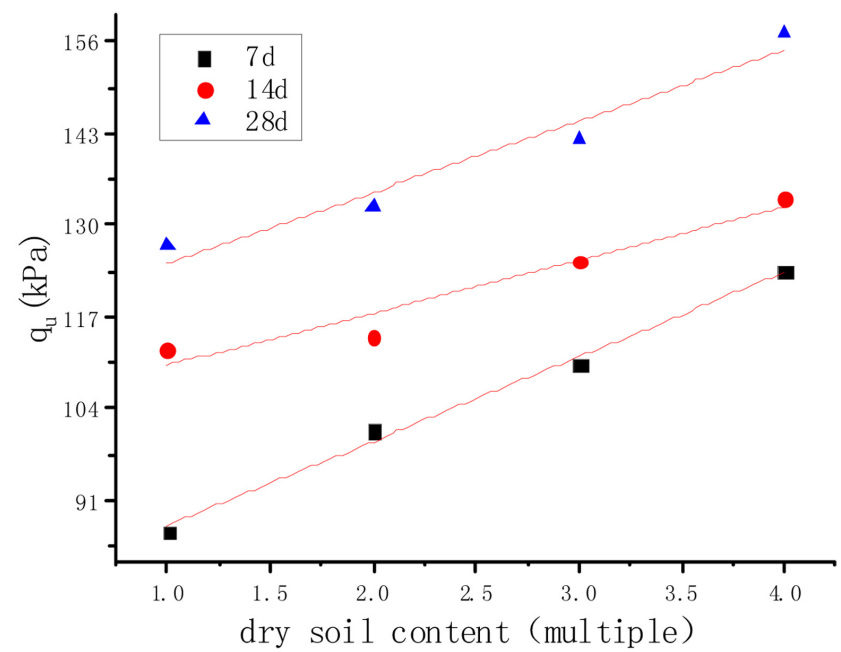

Figure 7. Cement content and $\mathrm{q}_{\mathrm{u}}$ fitting curve when cement is used alone. 


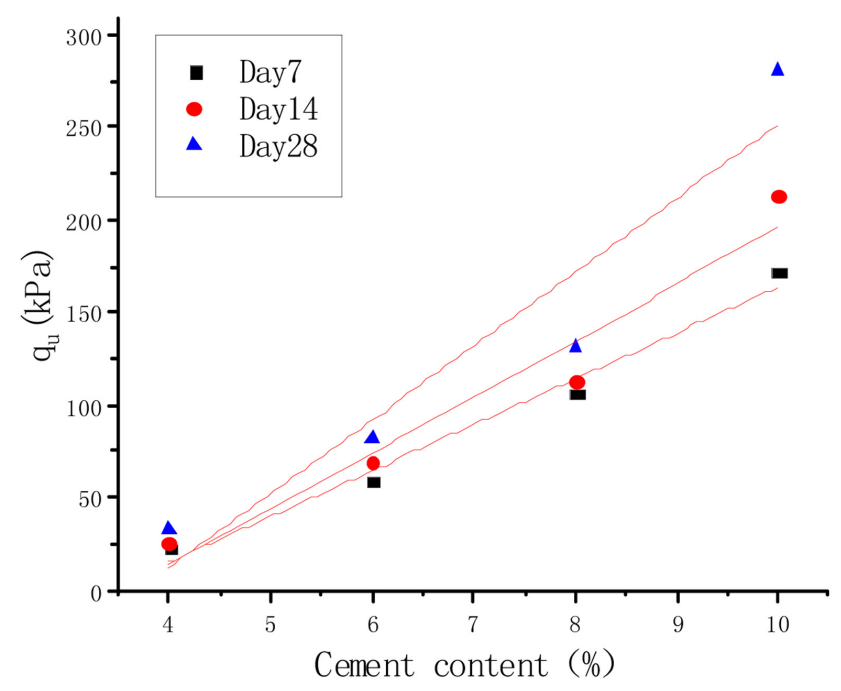

Figure 8. Dry soil content and $\mathrm{q}_{\mathrm{u}}$ fit curve when cement content is $8 \%$.

Table 5. Fitting formula of unconfined compression strength of solidified sludge under different curing agent dosage conditions.

\begin{tabular}{|c|c|c|c|c|}
\hline \multirow[t]{2}{*}{ Age } & \multicolumn{2}{|c|}{$\begin{array}{l}\text { Fitting of cement content and } \mathrm{q}_{\mathrm{u}} \\
\text { when cement is used alone }\end{array}$} & \multicolumn{2}{|c|}{$\begin{array}{l}\text { Fitting of dry soil content with } \mathrm{q}_{\mathrm{u}} \\
\text { when cement content is } 8 \%\end{array}$} \\
\hline & Fitting function & $\mathrm{R}^{2}$ & Fitting function & $\mathrm{R}^{2}$ \\
\hline $7 \mathrm{~d}$ & $y=24.81 x-84.209$ & 0.97655 & $y=11.959 x+75.485$ & 0.96096 \\
\hline $14 \mathrm{~d}$ & $y=30.32 x+107.688$ & 0.92141 & $y=7.437 x+102.698$ & 0.91101 \\
\hline $28 \mathrm{~d}$ & $y=39.92 x+102.698$ & 0.90239 & $y=10.059 x+114.529$ & 0.92986 \\
\hline
\end{tabular}

\subsection{Effect of Age on the Strength of Solidified Sludge}

As shown in Figures 9-11, the unconfined compression strength of the solidified sludge is enhanced with the increase of age under the three different curing agent dosages. From Figure 12, in the same set of tests, the strength of the solidified sludge at 28 days of age is about 1.34 times the intensity of $7 \mathrm{~d}$ in the age, i.e.: $\mathrm{q}_{\mathrm{u} 28}=1.34 \mathrm{q}_{\mathrm{u}}$, and the intensity at $14 \mathrm{~d}$ is about 1.12 times that at $7 \mathrm{~d}$, that is, $\mathrm{q}_{\mathrm{u} 14}=1.12 \mathrm{q}_{\mathrm{u} 7}$.

\subsection{Orthogonal Test Analysis}

Tables 6-8 are the calculation results of $\mathrm{R}$ values of different ages, where $\mathrm{K} 1, \mathrm{~K} 2$, and $\mathrm{K} 3$ represent the average values of unconfined compression strength at each level of each factor. At the same time, the difference $\mathrm{R}$ of the average intensity in each horizontal direction of the same factor (extreme difference $=$ the maximum value of the average intensity - the minimum value of the average intensity) was used to reflect the magnitude of the impact of changes in the horizontal direction of each factor on the test results (intensity). A very large extreme difference means that the change in the level of the factor has a large impact on the test results [10]. 


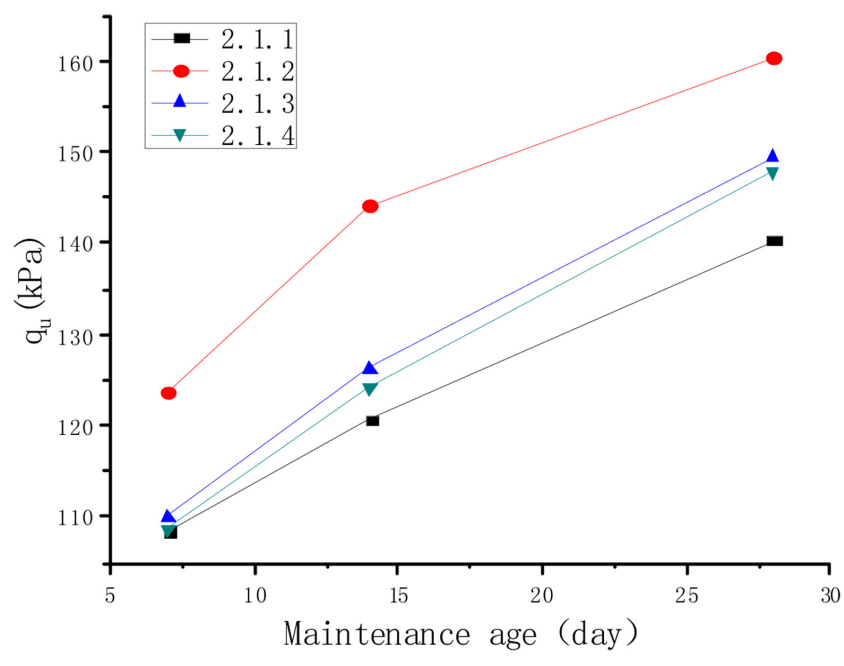

Figure 9. Effect of age on $\mathrm{q}_{\mathrm{u}}$ when cement content is different.

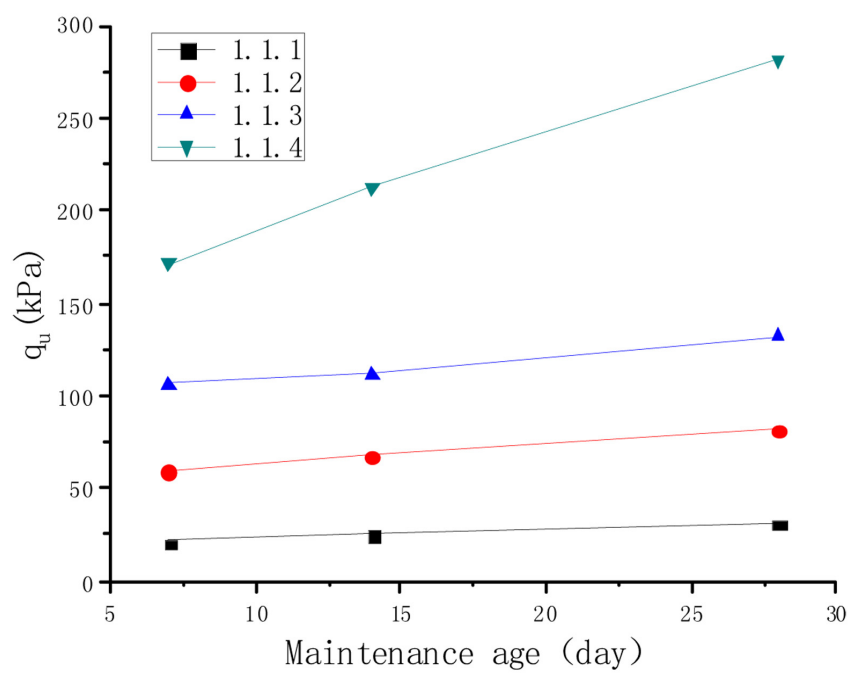

Figure 10. Effect of age on $\mathrm{q}_{\mathrm{u}}$ in the case of different gypsum content.

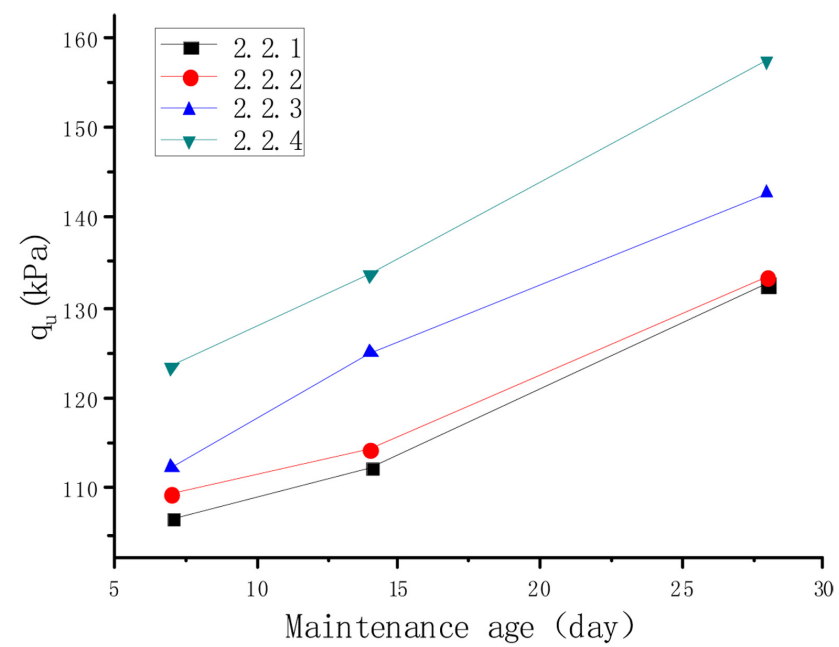

Figure 11. Effect of age on $\mathrm{q}_{\mathrm{u}}$ when dry soil content is different. 


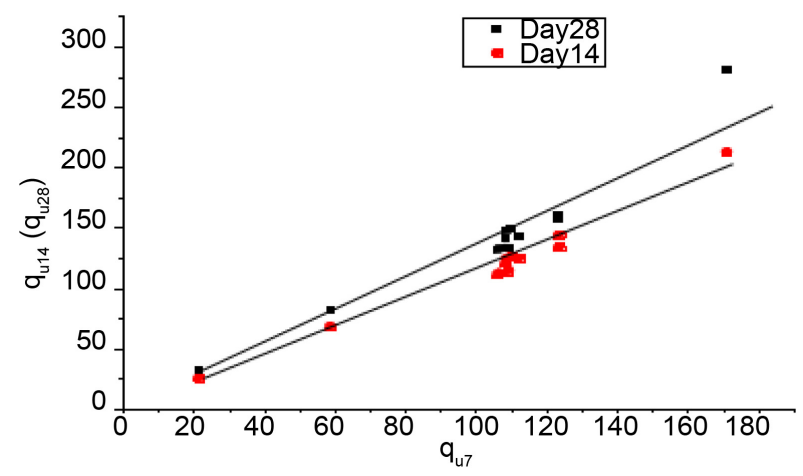

Figure 12. $\mathrm{q}_{\mathrm{u} 14}\left(\mathrm{q}_{\mathrm{u} 28}\right)-\mathrm{q}_{\mathrm{u} 7}$ relationship fitting curve.

Table 6. Calculation of $\mathrm{R}$ value at age $7 \mathrm{~d}$.

\begin{tabular}{cccc}
\hline & Cement & Plaster & Dry soil \\
\hline K1 & 35.26 & 84.48 & 90.20 \\
K2 & 97.22 & 105.33 & 85.69 \\
K3 & 138.96 & 81.63 & 95.54 \\
$\max$ & 138.96 & 105.33 & 95.54 \\
$\min$ & 35.26 & 81.63 & 85.69 \\
$\mathrm{R}$ & 103.70 & 23.70 & 9.85 \\
\hline
\end{tabular}

Table 7. Calculation of $\mathrm{R}$ value at age $14 \mathrm{~d}$.

\begin{tabular}{cccc}
\hline & Cement & Plaster & Dry soil \\
\hline K1 & 41.12 & 99.59 & 105.93 \\
K2 & 115.10 & 119.50 & 102.91 \\
K3 & 161.21 & 98.34 & 108.60 \\
$\max$ & 161.21 & 119.50 & 108.60 \\
$\min$ & 41.12 & 98.34 & 102.91 \\
$\mathrm{R}$ & 120.09 & 21.16 & 5.69 \\
\hline
\end{tabular}

Table 8. Calculation of $R$ value at age $28 \mathrm{~d}$.

\begin{tabular}{cccc}
\hline & Cement & Plaster & Dry soil \\
\hline K1 & 47.09 & 116.46 & 120.03 \\
K2 & 124.44 & 136.74 & 132.10 \\
K3 & 209.21 & 127.53 & 128.61 \\
$\max$ & 209.21 & 136.74 & 132.10 \\
$\min$ & 47.09 & 116.46 & 120.03 \\
$\mathrm{R}$ & 162.12 & 20.28 & 12.08 \\
\hline
\end{tabular}

In Tables 6-8, the $\mathrm{R}$ values of cement are 103.7, 120.09, and 162.12 at three different ages, which are the maximum influencing factors and are 5-8 times of the $R$ value of gypsum. The soil $R$ value is $10-24$ times, the cement content is the main factor, and the dry soil and gypsum content are secondary factors. 


\section{Conclusions}

1) The cement content and the dry soil content have a good linear relationship with the strength of the solidified sludge $y=A x+B(A>0)$, and the effect of cement content on the strength is higher than that of the dry soil. From the fitted function, the amount of curing agent can be estimated according to the strength requirements, and the actual engineering can be guided.

2) The age of the solidified sludge has a good linear relationship with the unconfined compression strength $\mathrm{q}_{\mathrm{u} 28}=1.34 \mathrm{q}_{\mathrm{u} 7}, \mathrm{q}_{\mathrm{u} 14}=1.12 \mathrm{q}_{\mathrm{u} 7}$. In this ratio, the strength of the late solidified sludge can be estimated from the strength value of $7 \mathrm{~d}$ in length.

3) It can be seen from the orthogonal test that the strength is affected by the three curing agents: cement content $>$ gypsum content $>$ dry soil content. Through experiments, it is determined that the optimal curing agent mix ratio was $8 \%$ of cement content, $30 \%$ of gypsum content (\% of cement content), and 4 times of dry soil content (multiple of cement content).

\section{Conflicts of Interest}

The authors declare no conflicts of interest regarding the publication of this paper.

\section{References}

[1] Yang, C.M. (2006) Research on the Environmental and Engineering Properties of Dewatered Sludge and Its Landfill Disposal Methods. School of Civil Engineering and Architecture, Tianjin University, Tianjin, 1-9.

[2] Chu, X., Liu, S.H., Wang, L.J., et al. (2010) Influence of Water Content and Potential Gradient on Soil Resistivity in Electroosmosis. Journal of Hohai University: Natural Science Edition, 38, 575-579.

[3] Lin, A.Z., Zheng, R.G. and Huang, Y.Z. (2006) Experimental Study on Solidified Sludge Mud as Filling Material. Journal of Ningbo University (Natural Science Edition), No. 4, 525-528.

[4] Sezer, A., Yilmaz, H.R. and Ramyavr, K. (2006) Utilization of a Very High Lime Fly Ash for Improvement of Izmir Clay. Building and Environment, 41, 150-155. https://doi.org/10.1016/j.buildenv.2004.12.009

[5] Filz, G.M., Hodges, D.K., Weatherby, D.E., et al. (2005) Standardized Definitions Laboratoryprocedures for Soil-Cement Specimens Applicable to the Wet Method of Deep Mixin. Innovation in Grouting and Soil Improvement, 162, 1-13. https://doi.org/10.1061/40783(162)1

[6] Lin, D.F., Lin, K.-L. and Hung, M.-J. (2007) Sludge Ash/Hydrated Lime on the Geotechnical Properties of Soft Soil. Journal of Hazardous Materials, 145, 58-64. https://doi.org/10.1016/j.jhazmat.2006.10.087

[7] Yong, R.N. and Ouhadi, V.R. (2007) Experimental Study on Instability of Bases on Natural and Lime/Cement-Stabilized Clayey Soils. Applied Clay Science, 35, 238-249. https://doi.org/10.1016/j.clay.2006.08.009

[8] Tremblay, H., Duchesne, J., Loea, J., et al. (2002) Influence of the Nature of Organic Compounds on Fine Soil Stabilization with Cement. Canadian Geotechnical Jour- 
nal, 39, 535-546. https://doi.org/10.1139/t02-002

[9] Cao, Y.-H., Yan, W. and Yang, C.-M. (2006) Experimental Study on Sludge Solidification. Journal of Tianjin University, 39, 199-203.

[10] Teng, H.Y., Zhu, G.Q., Huang, P. and Liu, P. (2008) Analysis of Orthogonal Experimental Design Cases. Pharmaceutical Care and Research, 8, 75-76. 